\title{
UJI TARIK BETON MEMADAT SENDIRI HIGH VOLUME FLY ASH 60\%
}

\author{
Agus Setiya Budi 1), Senot Sangadji ${ }^{2)}$, Kevin Ferdinand Pratama ${ }^{3)}$ \\ 1) Dosen Program Studi Teknik Sipil, Universitas Sebelas Maret Surakarta \\ 2) Dosen Program Studi Teknik Sipil, Universitas Sebelas Maret Surakarta \\ 3) Mahasiswa Program Studi Teknik Sipil, Universitas Sebelas Maret Surakarta \\ Jl. Ir. Sutami 36 A, Kentingan Surakarta 57126 \\ Email: Kferdinand63@gmail.com
}

\begin{abstract}
Self - Compacting Concrete (SCC) is one of construction innovation to solve casting and compaction problem. SCC has an ability to flow through complex reinforcement and fill spaces or formwork without a need for mechanic vibrating compaction. SCC concept is combined with $H V \mathrm{~F} A$ concept, that is the application of fly ash greater than 50\%. Fly Ash is a fine particle produced from coal combustion, which can be used to substitute cement in concrete production. This research examines about direct tensile test concrete on $60 \%$ fly ash using dimensions $10 \times 10 \times 25 \mathrm{~cm}$ with a timber triangle in the middle of the span with $2 \mathrm{~cm} \times 1.5 \mathrm{~cm}$. The result of this experiment, HVFAC with $60 \%$ fly ash content has a tensile strength of 2,429 MPa.
\end{abstract}

Keywords: Direct tensile, Fly ash, HVFA-SCC.

\begin{abstract}
Abstrak
Beton Memadat Sendiri adalah suatu inovasi pada dunia konstruksi untuk mengatasi permasalahan pengecoran dan pemadatan. SCC mampu mengalir melalui tulangan yang kompleks dan mengisi ruangan atau cetakan tanpa bantuan alat penggetar mekanik. Konsep SCC ini dipadukan dengan konsep HVFA, yaitu penggunaan fly ash dalam jumlah lebih besar dari $50 \%$. Fly Ash merupakan partikel halus yang terbuat dari hasil pembakaran batu bara, yang digunakan untuk mengganti penggunaan semen dalam pembuatan beton. Pada penelitian ini akan menganalisis uji kuat tarik beton pada penggunaan fly ash dengan kadar $60 \%$ berdimensi $10 \times 10 \times 25 \mathrm{~cm}$ dengan coakan berbentuk segitiga di tengah bentang dengan dimensi $2 \mathrm{~cm} \times 1,5 \mathrm{~cm}$. Hasil dari penelitian ini, disimpulkan bahwa beton HVFAC kadar fly ash 60\% memiliki nilai kuat tarik sebesar 2,429 MPa.
\end{abstract}

Kata kunci: Fly ash, HVFA -SCC, Uji kuat tarik

\section{PENDAHULUAN}

Dunia konstruksi mengalami perkembangan yang cukup pesat. Inovasi dalam teknologi yang digunakan pada dunia konstruksi pun semakin beragam. Salah satu inovasi yang muncul pada saat ini adalah pengembangan dan inovasi terhadap beton. Beton masih menjadi salah satu pilihan terdepan untuk konstruksi, dikarenakan beton memiliki berbagai macam kelebihan diantaranya bahan dengan kuat tekan tinggi, tahan terhadap api, harganya yang relatif murah, dan berbagai kelebihan lainnya, sehingga beton masih menjadi pilihan utama dan juga pengembangan terhadap beton sendiri semakin inovatif. Pada kenyataannya, permasalahan dalam dunia konstruksi masih banyak dijumpai dilapangan, salah satu contoh permasalahan yang ada yaitu pada pekerjaan pengecoran beton dan pemadatan. Banyak dari para pekerja cukup kesulitan menghadapi pekerjaan tersebut dikarenakan desain tulangan yang kian kompleks serta jarak antar tulangan yang rapat, sehingga membutuhkan beton khusus yang memudahkan pekerjaan pengecoran. Oleh karena itu, muncul gagasan inovasi beton berupa beton SCC.

SCC merupakan beton segar yang dapat mengalir melalui tulangan dan mengisi cetakan secara padat tanpa bantuan alat pemadat mekanik (Tjaronge et al., 2006) dan (Hartono et al., 2007). SCC memiliki sifat fisik kecairan (fluidity) yang memastikan tingkat homogenitas yang tinggi, meminimalkan pori dan menyeragamkan kuat tekan beton, serta memberikan potensi untuk memberikan penyelesaian dan daya tahan terhadap struktur yang sangat baik (EFNARC, 2005), sehingga beton SCC merupakan pilihan yang tepat untuk digunakan pada struktur yang mempunyai tulangan yang rapat dan kompleks yang membutuhkan beton dengan tingkat workability tinggi dan permeabilitas rendah.

Industri beton yang masih menggunakan semen portland sebagai bahan baku utamanya memicu peningkatan efek rumah kaca (greenhouse effect). Hal ini dapat terjadi dikarenakan emisi karbon dioksida yang berasal dari proses pembakaran batu kapur dan juga pembakaran batu bara pada produksi semen portland, sehingga hal tersebut memicu terjadinya peningkatan pemanasan global (global warming). Meskipun penggunaan semen portland dalam pembuatan beton masih tidak bisa dihindari, akan tetapi banyak upaya yang sedang dilakukan agar penggunaan semen dapat dikurangi, dan salah satu upaya yang dilakukan adalah pemanfaatan bahan tambah semen seperti fly ash, silica fume, metakaolin, dan lainnya. (Wallah et al., 2006). 
Pada penelitian ini, bahan tambah untuk mengurangi kadar semen dalam powder yang digunakan adalah fly ash. Fly Ash adalah partikel halus berukuran antara 1-150 mikrometer yang terbuat dari sisa sisa pembakaran batu bara. Kadar oksida terbanyak di dalam fly ash adalah silica $\left(\mathrm{SiO}_{2}\right)$ sebanyak $60-70 \%$ berat. (Caroles, 2019). Sifat kimia tersebut berfungsi sebagai bahan pengikat dalam pembuatan beton atau sifat pozzolan yang mana sifat tersebut sama seperti sifat semen.

Pada awalnya, penggunaan fly ash hanya digunakan sebagai bahan tambah dalam pembuatan beton dengan kadar 5\%-20\% yang bertujuan untuk menambah sifat plastisitas adukan beton dan kekedapan beton (Suhud, 1993). Penggunaan fly ash dalam pembuatan beton dinilai masih sangat terbatas dan masih belum maksimal. Untuk itu, penggunaan fly ash pada beton ditingkatkan hingga kadar minimum $50 \%$ dari berat binder atau disebut konsep High Volume Fly Ash Concrete (HVFAC). Dengan inovasi tersebut, sangat memungkinkan untuk mendapatkan beton yang mudah dikerjakan (workability), berkualitas tinggi (good performance), dan daya tahan tinggi (durability) (Mehta, 2006).

Kuat tarik merupakan salah satu unsur penting dari beton karena dapat mempengaruhi perilaku retak dari suatu beton. Dari beberapa metode pengujian untuk kuat tarik, metode Direct Tensile dinilai lebih efektif, efisien, dan juga rasional dibandingkan pengujian kuat tarik yang lain. Dalam pengujian Direct Tensile (kuat tarik langsung), nilai kuat tarik lebih mendekati yang sebenarnya dikarenakan pada pengujian kuat tarik langsung seluruh penampang akan memikul tegangan tarik yang merata. (Pandaleke, R. et al., 2017). Berdasarkan latar belakang tersebut, akan dikaji dan dianalisis Uji Tarik Beton Memadat Sendiri HVFA 60\%.

\section{METODE PENELITIAN}

Penelitian ini bersifat eksperimental, yang mana digunakan benda uji dengan karakteristik HVFA - SCC Kadar $60 \%$ berupa beton dengan dimensi $10 \times 10 \times 25 \mathrm{~cm}$ yang dilengkapi dengan baja drat pada ujung atas dan ujung bawah sepanjang $17 \mathrm{~cm}$, yang mana $10 \mathrm{~cm}$ tertanam didalam beton dan $7 \mathrm{~cm}$ diluar beton. Pengujian ini dilakukan dengan menggunakan metode load-controlled test. Pertambahan panjang (displacement) diukur dengan menggunakan alat Linear V ariable Displacement Transducer (LVDT) dengan kapasitas $1 \mathrm{~cm}$ yang disambungkan dengan alat LVDT Indicator sebagai alat untuk membaca displacement yang terjadi.

Pengujian beton segar SCC pada penelitian ini mengacu pada standar EFNARC tahun 2005 yang meliputi pengujian flow table test dan $v$-funnel test untuk memeriksa kemampuan beton dalam mengalir (flowablitiy), serta l-box test untuk memeriksa kemampuan beton untuk melewati tulangan (passability). Tujuan dari pengujian ini dimaksudkan untuk memeriksa apakah campuran beton SCC yang diproduksi sudah memenuhi standar beton segar SCC.

\section{Self-Compacting Concrete (SCC)}

Inovasi Beton Memadat Sendiri muncul pertama kali dan dikembangkan di Jepang sekitar 30 yang lalu yang difungsikan untuk mencapai struktur beton yang tahan lama. Beton memadat sendiri merupakan beton yang dapat mengalir, mengisi cetakan, dan memadat secara mandiri tanpa perlu adanya bantuan pemadatan. Beton memadat sendiri memerlukan adanya penambahan zat aditif berupa superplasticizer, selain itu komposisi dan ukuran agregat yang digunakan lebih kecil daripada komposisi dan ukuran agregat pada pembuatan beton konvensional.

\section{High Volume Fly Ash Concrete (HVFAC)}

High Volume Fly Ash Concrete (HVFAC) adalah penggunaan fly ash pada beton sebagai bahan pozzolan yang mana prosentase penggunaannya mencapai lebih dari $50 \%$ berat total binder. Penelitian yang dilakukan pada fly ash sebagai bahan pozzolan yang mengurangi kadar semen di campuran beton dengan prosentase $60 \%$ telah dilaporkan berhasil (Hardjito dan Rangan, 2005). Beton HVFAC telah terbukti lebih tahan lama (durability) dan lebih hemat dalam aspek sumber daya alam jika dibandingkan dengan beton OPC (Malhotra, 2002).

HVFAC sudah teruji langsung di lapangan, sebagai contoh penerapan $H V F A C$ adalah pembangunan jalan yang ada di India. Dalam pengaplikasiannya, kadar OPC sebesar 50\% digantikan dengan fly ash (Desai, 2004). Penggunaan fly ash dapat meningkatkan workability, flow ability, pumpability, mengurangi panas hidrasi, serta meningkatkan resistensi terhadap serangan sulfat, reaktivitas alkali silika (ASR) dan jenis lain dibandingk an dengan campuran beton normal (Solis et al, 2010). HFVAC memiliki high durability terhadap korosi tulangan (reinforcement corrosion), ekspansi alkali silika, serangan sulfat, dan juga memiliki stability yang sangat baik terhadap retak dari susut termal, penyusutan autogenous, dan pengeringan susut (Mehta, 2004). 


\section{Uji Kuat Tarik}

Uji kuat tarik ini mengacu pada penelitian Faez Alhussainy dkk, Direct Tensile Testing of Self-Compacting Concrete tahun 2016. Pengujian ini menggunakan benda uji berupa beton berdimensi $10 \times 10 \times 25 \mathrm{~cm}$ yang dilengkapi dengan baja drat pada ujung atas dan ujung bawah sepanjang $17 \mathrm{~cm}$, yang mana $10 \mathrm{~cm}$ tertanam didalam beton dan $7 \mathrm{~cm}$ diluar beton kemudian pada tengah bentang, diberi coakan berbentuk segitiga dengan dimensi alas $2 \mathrm{~cm}$ dan tinggi 1,5 $\mathrm{cm}$ yang berfungsi untuk memastikan kegagalan terjadi pada area coakan. Benda uji yang digunakan dapat dilihat pada Gambar 1.

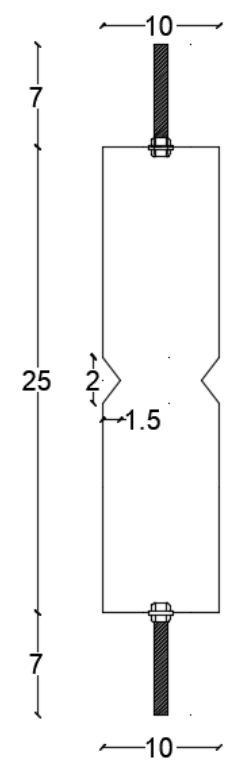

Gambar 1. Benda uji kuat tarik

Kuat tarik dengan pengujian ini dapat dihitung dengan persamaan berikut:

$f_{t}=\frac{P}{A}$

Keterangan:

$\mathrm{f}_{\mathrm{t}} \quad=$ nilai kuat tarik $(\mathrm{MPa})$

$\mathrm{P} \quad=\operatorname{beban}(\mathrm{N})$

A = luas penampang efektif $\left(\mathrm{mm}^{2}\right)$

\section{HASIL PENELITIAN}

Hasil Uji Material

Hasil uji agregat halus dapat dilihat pada Tabel 1.

Tabel.1 Hasil uji agregat halus

\begin{tabular}{lccc}
\hline \multicolumn{1}{c}{ Jenis Uji } & Hasil Uji & Kriteria & Keterangan \\
\hline Berat Jenis SSD & $2,475 \mathrm{gr} / \mathrm{cm}^{3}$ & $2,4-2,6 \mathrm{gr} / \mathrm{cm}^{3}$ & Memenuhi \\
Kadar Lumpur & $0,5 \%$ & Maksimal $5 \%$ & Memenuhi \\
Kadar Zat Organik & Warna Kuning Muda & Warna Kuning Muda & Memenuhi \\
\hline
\end{tabular}

Hasil uji agregat kasar ditampilkan pada Tabel 2.

Tabel.2 Hasil uji agregat kasar

$\begin{array}{llll}\text { Jenis Uji } & \text { Hasil Uji } & \text { Kriteria } & \text { Keterangan }\end{array}$




\begin{tabular}{lccc}
\hline Berat Jenis SSD & $2,7 \mathrm{gr} / \mathrm{cm}^{3}$ & $2,5-2,7 \mathrm{gr} / \mathrm{cm}^{3}$ & Memenuhi \\
Keausan Agregat & $26,92 \%$ & $<50 \%$ & Memenuhi \\
\hline
\end{tabular}

\section{Hasil Uji Beton Segar Kadar 60\%}

Hasil uji beton segar ditampilkan pada Tabel 3 .

Tabel.3 Hasil uji beton segar kadar 60\%

\begin{tabular}{lcccc}
\hline \multicolumn{1}{c}{ Jenis Uji } & Parameter & Hasil Uji & Kriteria & Keterangan \\
\hline Flow Table Test & $D(\mathrm{~mm})$ & 590 & $550-850 \mathrm{~mm}$ & Memenuhi \\
L-Box Test & $\mathrm{t}_{50}(\mathrm{~s})$ & 4 & $2-5$ detik & Memenuhi \\
$V$ - Funnel Test & $\mathrm{h}_{2} / \mathrm{h}_{1}$ & 0,90 & $0,8-1,0$ & Memenuhi \\
& $\mathrm{T}(\mathrm{s})$ & 6 & $6-12$ detik & Memenuhi \\
\hline
\end{tabular}

\section{Hasil Uji Kuat Tarik}

Data yang diambil pada uji kuat tarik diperoleh dari pembacaan LVDT Indicator dan kemudian di plot menjadi grafik hubungan Load - Displacement yang disajikan pada Gambar 2 berikut:

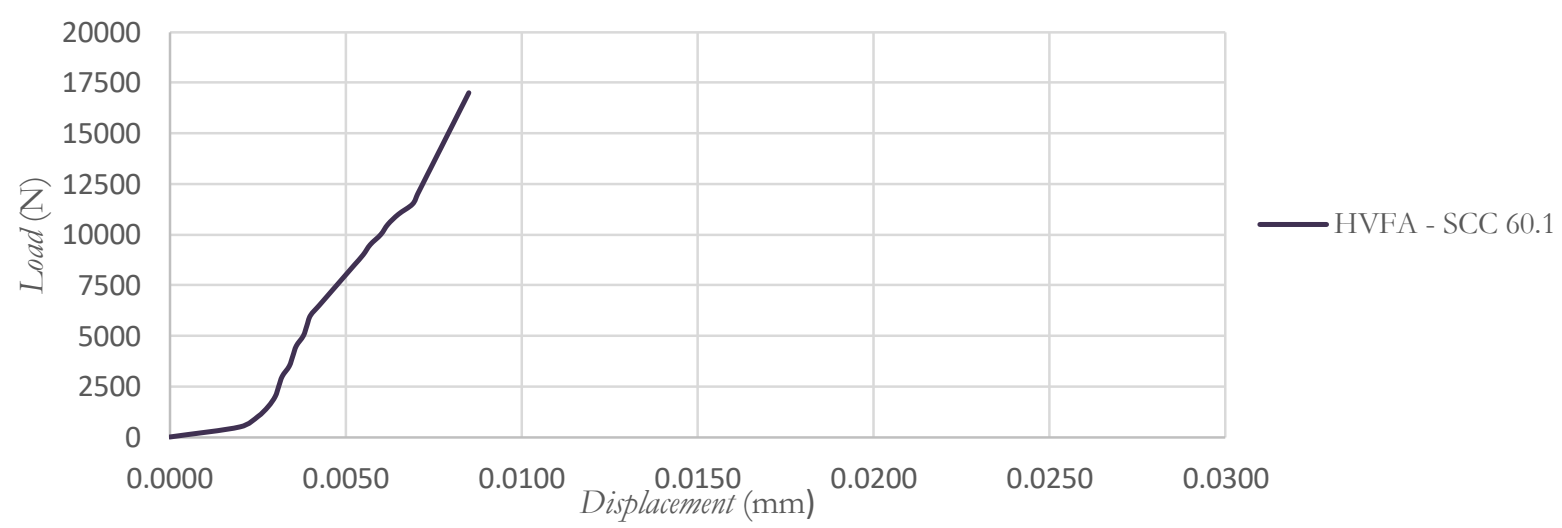

Gambar 2. Grafik Load-Displacement HVFA - SCC Kadar 60\%

Dari grafik, didapat nilai Load-Displacement maksimum Uji Tarik Beton Memadat Sendiri High Volume Fly Ash 60 \% yang dapat dilihat pada Tabel 4:

Tabel.4 Nilai load-displacement maksimum

\begin{tabular}{cc}
\hline \multicolumn{2}{c}{ HVFA - SCC 60.1 } \\
\hline Load Maksimum $(\mathrm{N})$ & 17.000 \\
Displacement Maksimum (mm) & 0,0085 \\
\hline
\end{tabular}

Dari nilai Load-Displacement maksimum, dilakukan perhitungan nilai kuat tarik yang dapat dilihat sebagai berikut:

$$
\begin{array}{ll}
\mathrm{P} & =24.500 \mathrm{~N} \\
\text { A-efektif } & =\mathrm{pef}_{\mathrm{ef}}=100 \times 70=7000 \mathrm{~mm}^{2} \\
\mathrm{ft} & =\frac{P}{\text { A-efekti }} \\
& =\frac{2450 \mathrm{C}}{7000} \\
& =2,429 \mathrm{MPa}
\end{array}
$$

Hasil dari perhitungan nilai kuat tarik dapat dilihat pada Tabel.5 sebagai berikut: 
Tabel.5 Nilai kuat tarik beton memadat sendiri

\begin{tabular}{cccc}
\hline Benda Uji & $\begin{array}{c}\mathbf{P} \\
\mathbf{( N )}\end{array}$ & $\begin{array}{c}\text { A-efektif } \\
\left(\mathbf{m m}^{\mathbf{2}}\right)\end{array}$ & $\begin{array}{c}\mathbf{f}_{\mathbf{t}} \\
\mathbf{( M P a})\end{array}$ \\
\hline$H V F A-S C C 60.1$ & 17.000 & 7.000 & 2,429
\end{tabular}

\section{KESIMPULAN}

Hasil penelitian uji tarik beton memadat sendiri adalah sebagai berikut:

1. Nilai Load-Displacement maksimum kuat tarik langsung beton HVFA - SCC Kadar $60 \%$ sebesar 17.000 N; $0,0085 \mathrm{~mm}$;

2. Nilai kuat tarik langsung beton HVFA - SCC dengan menggunakan kadar fly ash sebesar $60 \%$ menghasilkan kuat tarik sebesar 2,429 $\mathrm{MPa}$.

\section{REFERENSI}

Anonim, 1998, “ ASTM C40-97 : Test Method for Organic Impurities in Fine Aggregates for Concrete”. Annual Books of ASTM Standards Designation.

Anonim, 2002, " ASTM C469 : Standard Test Method for Static Modulus of Elasticity and Poisson's Ratio of Concrete in Compression," American Society for Testing and Materials, Pennsylvania.

Anonim, 2003, “C117-03 : Standard Test Method for Materials Finer than 75-Mm (No. 200) Sieve in Mineral Aggregates by Washing”, United States: ASTM International.

Anonim, 2005, “ASTM C618-05 : Standard Specification for Coal Fly Ash and Raw or Calcined Natural Pozzolan For Use in Concrete".

Anonim, 2005, “ASTM C136 : Standard Test Method for Sieve Analysis of Fine and Coarse Aggregates”, Annual Book of Standards 4(02).

Anonim, 2005, "The European Guidelines for Self-Compacting Concrete: Specification, Production and Use". International Bureau for Precast Concrete (BIBM).

Anonim, 2006, "ASTM C131-06 : Standard Test Method for Resistance to Degradation of Small-Size Coarse Aggregate by Abrasion and Impact in the Los Angeles Machine".

Anonim, 2008, “SNI 1970- 2008 : Cara Uji Berat Jenis dan Penyerapan Air Agregat Halus”. BSN, Jakarta.

Anonim, 2012, “ASTM C127-12 : Standard Test Method for Density, Relative Density (Specific Gravity), and Absorption of Coarse Aggregate".

Caroles, J. D. S., 2019, “Ekstraksi Silika yang Terkandung Dalam Limbah Abu Terbang Batu Bara”, Fullerene Journal of Chemistry. Vol. 4 No. 1, pp. 5-7.

Davidovits, J., 1999, “Chemistry of Geopolymer System, Terminology”, Paper Presented at The Geopolymer '99 International Conference, Saint-Quentin, France.

Dehn, F., Holschemacher, K., \& Weiße, D, 2000, "Self-Compacting Concrete (SCC) Time Development of The Material Properties and the Bond Behaviour", LACER No 5 2000, August 2015, 115-124.

Desai, J. P, 2004, "Construction of HVFA Concrete Pavements in India: Four Case Studies". Indian Concrete Journal. Vol. 78 No. 11, pp. 62-64.

Faez ,Alhussainy., Hayder Alaa Hasan., Sime, Rogic., M. Neaz Sheikh., Muhammad N.S. Hadi., 2016, “Direct Tensile Testing of Self-Compacting Concrete", School of Civil, Mining, And Environmental Engineering, University of Wollongong, Australia.

Grünewald, S., 2004, "Performance-Based Design of Self-Compacting Fibre Reinforced Concrete", Delft University Press, Belanda.

Hardjito, Djwantoro, 2014, “Abu Terbang Solusi Pencemaran Semen”, Igarss 2014 (1): 1-5.

Hartono, 2007, "Pertimbangan Pada Perbaikan dan Perkuatan Struktur Bangunan Pasca Gempa", Seminar HAKI, Jakarta.

Kosakoy, M. N. M., Wallah, S. E., \& Pandaleke, R, 2017, "Perbandingan Nilai Kuat Tarik Langsung dan Tidak Langsung Pada Beton yang Menggunakan Fly Ash", Jurnal Sipil Statik. Vol. 5 No. 7.

Malhotra, V. M, 2002, "High-Performance High-Volume Fly Ash Concrete", ACI Concrete International, Vol. 24, pp. 1-5. 
Mehta, P. K., 2004, "High Performance, High-Volume Fly Ash Concrete for Sustainable Development". Proceedings of International Workshop on Sustainable and Concrete Technology. Beijing, China, 20-21 Mei 2003, Center for Trnsportation Research and Education, Iowa State University, Ames, Iowa, USA.

Tjaronge, M. Wihardi, et al., 2006, "Pecahan Marmer Sebagai Pengganti Parsial Agregat Kasar Self Compacting Concrete (SCC)", Jurnal Desain \& Konstruksi. Vol.5 No. 1, pp. 1-9. 